\title{
BACTERIOLOGICAL AND PATHOLOGICAL INVESTIGATION OF GOAT LUNGS IN MYMENSINGH AND DETERMINATION OF ANTIBIOTIC SENSITIVITY
}

\author{
M. M. Rashid, M. J. Ferdoush, M. Dipti, P. Roy, M. M. Rahman, M. I. Hossain and M. M. Hossain* \\ Department of Pathology, Faculty of Veterinary Science, Bangladesh Agricultural University, \\ Mymensingh-2202
}

\begin{abstract}
The foremost important goal of the present study was to investigate the bacteriological and pathological conditions in lungs of goats slaughtered in four different slaughter houses/places of Mymensingh Sadar, Mymensingh and in addition to it, antibiotic sensitivity test of commonly used antibiotics in Veterinary practices were performed on isolated bacteria. A total of 75 lungs of slaughtered goats were examined individually and out of which 20 affected lungs were collected for histopathology and bacterial isolation respectively from Mymensingh Sadar, Mymensingh in Bangladesh, during the period from January to May 2013.The lung lesions was grossly recorded $40 \%$ in goats (30 out of 75 lungs examined). Grossly, the lung lesions were categorized into (a) hemorrhages $35 \%$ (b) congestion $25 \%$ (c) hemorrhage and congestion $15 \%$ (d) emphysematous lung $15 \%$ and (e) hepatization in lung $10 \%$. In histopathology, lung lesions were categorized into (a) bronchopneumonia $30 \%$, (b) pneumonia $25 \%$ (c) hemorrhagic pneumonia $20 \%$ (d) emphysema $15 \%$, (e) purulent pneumonia $10 \%$. Pasteurella sp. (15\%) was isolated from the lung lesions of hemorrhagic pneumonia, E. coli. (25\%) from bronchopneumonia and Staphylococcus sp. (40\%) from purulent pneumonia, focal pneumonia and emphysema, and mixed infection (Staphylococcus sp. and E. coli) 20\%. Finally antibiotics sensitivity test was performed on isolated bacteria to which ciprofloxacin was more powerful than others (penicillin, amoxicillin, streptomycin, nalidixic acid and kanamycin) tested and the second one was oxytetracyclin.
\end{abstract}

Key words: Bacteria, pathology, goat lung, antibiotic sensitivity

\section{INTRODUCTION}

Lung, the important organ of respiratory system, is vulnerable to many infectious and non-infectious agents causing various pathological conditions in farm animals. Among the inflammatory and non-inflammatory disease conditions, pneumonia either acute or chronic causes debility and death leading to great economic loss to the farmers and distress (Alam et al., 2001; Ferdausi et al., 2008). Women rear only few goats that are grazed usually on free pastures. These pastures are usually found to be contaminated with various infectious agents that can get access through inhalation and thus they cause pneumonia. A large number of goats are being brought to the Veterinary Clinics in different parts of Bangladesh for their treatment. Among them, a considerable number is of respiratory problem, especially pneumonia. A variety of causes are responsible for development of pneumonia (Rahman et al., 1976). The knowledge of pathogenesis, gross, microscopic changes of lung and antibiotics sensitivity test on isolated bacteria will help the veterinarian for diagnosis and treatment of the diseases. Related works in the context of Bangladesh on goat lungs lesions are very rare. This paper describes the occurrence of lung lesions, gross and microscopic changes and isolation, identification of bacteria from the affected lungs and also to determine antibiotics sensitivity test on isolated bacteria.

\section{MATERIALS AND METHODS \\ Collection of samples}

The samples were collected from four slaughter houses/places of Mymensingh Sadar (Masua bazar, KR market, Bolashpur and Kewatkhali). Lungs were collected from goats immediately after slaughter. A total of 20 affected lungs out of 75 examined were collected for pathological studies and 20 swabs were collected from inner core of lungs by cotton bud aseptically and immediately placed in Falcon tube containing 10ml nutrient broth for isolation of bacteria. All the samples were transferred to the Histopathology and Bacteriology Laboratory, Department of Pathology, Bangladesh Agricultural University, Mymensingh for histopathology, isolation and identification of bacteria respectively.

\section{Gross pathology}

A total of 20 samples were examined for gross abnormalities of lungs. Gross tissue changes were observed and recorded carefully, and representative tissue samples containing lesions were fixed in 10\% neutral buffered formalin for histopathological studies at least for 3-7 days.

*Corresponding e-mail address: mmhossain04@yahoo.com.au 


\section{M. Rashid and others}

\section{Histopathology}

The formalin-fixed 20 lung tissues containing lesion were trimmed, processed, sectioned and stained as per standard procedure (Luna, 1968).

\section{Isolation and identification of bacteria}

Swabs from each of 20 lung samples were incubated for 24 hours at $37^{\circ} \mathrm{C}$. From the nutrient broth, subcultures were made in nutrient agar, blood agar, and EMB agar and incubated at $37^{\circ} \mathrm{C}$ for overnight. The identification of the organisms was performed by the tests as described by Alam et al. (2001), Ferdausi et al. (2008) and Tonu et al. (2011). On the basis of colony and staining characters the bacteria were grouped into four types: Pasteurella sp., E. coli, Staphylococcus sp., and mixed colonies of Staphylococcus sp. and E. coli. . Two representative samples of Pasteurella sp. and three of E. coli were tested for biochemical test using sugars.

\section{Polymerase chain reaction (PCR) for the detection of $E$. coli}

PCR is a powerful technique used for DNA amplification. PCR was carried out in the present experiment in a final reaction volume of 25 - 200 $\mu$ l capacity thin walled PCR tubes in a programmable thermocycler using Promega PCR Master Mix Kit. The primers (Tonu et al., 2011) used for the detection of the E. coli were shown in Table 1.

Table 1. Prmers used for the detection of E. coli

\begin{tabular}{|llc|}
\hline Primer & Primer sequence (5'-3') & Amplification products (bp) \\
\hline ECO-f & GACCTCGGTTTAGTTCACAGA & 585 \\
ECO-r & CACACGCTGACGCTGACCA & \\
\hline
\end{tabular}

Table 2.Composition of reaction mixture for PCR per reaction

\begin{tabular}{|lc|}
\hline \multicolumn{1}{|c|}{ Component } & Volume/ reaction \\
\hline PCR Master Mix & $12.5 \mu \mathrm{l}$ \\
Primer Forward $(100 \mathrm{pmol} / \mu \mathrm{l})$ & $0.5 \mu \mathrm{l}$ \\
Primer Reverse $(100 \mathrm{pmol} / \mu \mathrm{l})$ & $0.5 \mu \mathrm{l}$ \\
Nuclease free water & $6.5 \mu \mathrm{l}$ \\
\hline Total (Master mix) & $20 \mu \mathrm{l}$ \\
\hline
\end{tabular}

Five microliter water was added instead of DNA to the control tube. The tube was then centrifuged shortly in mini centrifuge machine.

\section{Thermal profile}

Specific primers ECO-f and ECO-r targeting $16 \mathrm{~S}$ rDNA were used in amplification reaction with a thermal profile :initial denaturation at $94^{\circ} \mathrm{C}$ for $3 \mathrm{~min}$, followed by 35 cycles for $94^{\circ} \mathrm{C}$ for 30 seconds, annealing at $60^{\circ} \mathrm{C}$ for $1 \mathrm{~min}$, and extension at $68^{\circ} \mathrm{C}$ for $2 \mathrm{~min}$, with a final extension at $68^{\circ} \mathrm{C}$ for 7 minutes and reaction was hold at $4^{\circ} \mathrm{C}$ (Tonu et al., 2011).

\section{Electrophoresis of the amplified products and documentation}

Agarose gel electrophoresis was conducted in $1 \mathrm{X}$ TAE buffer at $90 \mathrm{~V}$ for 30 minutes. One molecular weight marker 100bp DNA ladder size was electrophoresed alongside the PCR products. DNA bands were observed under UV light on a transilluminator and photographed by image documentation system.

\section{Antibiotics sensitivity test}

After preparation of nutrient agar plate, $20 \mu \mathrm{l}$ of nutrient broth containing culture of bacteria was poured on agar plate and it was spread by L-shaped ladder. 
Then prepared filter paper disc and commercial antibiotics disc (penicillin, amoxicillin, streptomycin, nalidixic acid and kanamycin) were placed on the agar plate by same distance according to centre by sterile forceps. Then it was incubated at $37^{\circ} \mathrm{C}$ for over night. No growth of bacteria around the particular disc was considered as sensitive to that antibiotic, growth of bacteria around the disc was considered as resistance to that particular antibiotic and partial growth was considered as partially resistant to that particular antibiotic (Dipti, 2013).

\section{RESULTS}

A total of 75 goat lungs were examined and 30 were found to be apparently abnormal in naked eye (Table 3 ). Out of 30 abnormal lungs, 20 were collected for pathological and bacteriological investigation. The occurrence of affected goats with lung disorders at 4 slaughter houses/places was about $40 \%$. Grossly the lung lesions were categorized into following types: (a) Hemorrhages 35\% (b) Congestions 25\% (Fig. 3) (c) hepatization (red and gray) of lungs 10\% (Fig. 1 and 2), (d) hemorrhage and congestions 15\% (e) Emphysema 15\% (Table 4).

In histopathology, the lung lesions were categorized into: (a) pneumonia $25 \%$ (Fig. 3), (b) bronchopneumonia $30 \%$ (Fig. 4 and 5), (c) emphysema 15\% (Fig. 5), (d) purulent pneumonia 10\%, and (e) hemorrhagic pneumonia 20\% ( Fig. 5, Table 5).

The prevalence of Pasteurella sp. was 15\% (Fig. 7), E. coli 25\%, Staphylococcus sp. 40\% and mixed infection (Staphylococcus sp. and E. coli) 20\%. Pasteurella sp. was isolated from pneumonia and hemorrhagic pneumonia. E. coli was isolated from hemorrhagic pneumonia, pneumonia (severe) and bronchopneumonia. Staphylococcus sp. isolated from emphysema, bronchopneumonia and purulent focal pneumonia (Fig. 6).

\section{a) Pneumonia}

The prevalence of pneumonia was recorded $25 \%$ ( 5 out of 20 lungs). There was presence of hemorrhages and in some cases congestion in lung. Microscopically, there was excessive hemorrhages within the alveoli and inter alveolar septa associated with leukocytic infiltration. Haemorrhage and leukocytic infiltration were found in the bronchus. The wall of the bronchus also showed the inflammatory changes and mild necrosis in the mucosal layer. The lesions of 5 lungs were variable.

\section{b) Broncho- pneumonia}

The prevalence of broncho-pneumonia was recorded 30\% (6 out of 20 lungs). The affected portion of lung was congested. In addition, the lung was consolidated on palpation. Microscopically, all 6 lungs showed exudates and infiltration of inflammatory cells mainly neutrophils in the bronchiolar wall as well as in the lumen of bronchiole. There was also deposition of exudates within the bronchi and alveoli.

\section{c) Purulent pneumonia}

The prevalence of purulent pneumonia was recorded 10\% (2 out of 20 lungs). All 2 lungs showed hepatization (1 red and 1 gray). Microscopic lesions were characterized by the presence of inflammatory cells consisted of mainly neutrophils within the alveoli and in the lumen of the bronchioles in lung with gray hepatization while other one showed same lesions but with increased level of erythocytes in alveoli of lung which was the characteristics of red hepatization. In addition to this, adjacent to the bronchioles, there were focal infiltrations of large number of neutrophils and few lymphocytes .

\section{d) Hemorrhagic pneumonia}

The prevalence of hemorrhagic pneumonia was recorded $20 \%$ (4 out of 20 lungs). The lungs showed severe hemorrhage and congestion in all 4 lungs. Microscopically, there was excessive hemorrhages within the alveoli and inter alveolar septa associated with leukocytic infiltration. Hemorrhages and leukocytic infiltration were also found in the bronchus. The wall of the bronchus also showed the inflammatory changes. All 4 lungs did not show the similar level of intensity of hemorrhage.

\section{(e) Emphysema of lung}

The prevalence emphysema of lung was recorded 15\% (3 out of 20 lungs). Emphysematous areas of all 3 lungs showed pale colour with elevated areas and that was easily diagnosed by compression of finger. Microscopically, many alveoli were distended and many had wide opening into each other or into a common space due to rupture of alveolar walls. The alveolar wall was thin and atrophic. 


\section{M. Rashid and others}

\section{B. Bacterial isolation and identification}

Out of 20 lungs 3 were positive to Pasteurella sp. (15\%), 5 were positive to E. coli $(25 \%), 8$ were positive to Staphylococcus sp. (40\%) and 4 others were found to be mixed infection (20\%) (Table 6).

Table 3. Investigation of goat after slaughtering

\begin{tabular}{|lccc|}
\hline $\begin{array}{l}\text { Name of the slaughter } \\
\text { houses/places }\end{array}$ & $\begin{array}{c}\text { No of goat } \\
\text { examined }\end{array}$ & No of goat affected & \% Affected \\
\hline Masua bazar, Sadar & 35 & 15 & 42.86 \\
Kewatkhali & 20 & 10 & 50 \\
KR market & 12 & 2 & 16.67 \\
Bolashpur & 8 & 3 & 37.5 \\
\hline Total & 75 & 30 & 40 \\
\hline
\end{tabular}

Table 4. Gross pathology of lung $(\mathrm{N}=20)$

\begin{tabular}{|lcc|}
\hline Lung lesions & No. of lung affected & \%Affected \\
\hline Hemorrhage & 7 & 35 \\
Congestion & 5 & 25 \\
Hemorrhage and congestion & 3 & 15 \\
Emphysema of lung & 3 & 15 \\
Hepatization of lung & 2 & 10 \\
\hline
\end{tabular}

Table 5. Histopathology of lung $(\mathrm{N}=20)$

\begin{tabular}{|lcc|}
\hline Lung lesions & No. of lung affected & \% Affected \\
\hline Pneumonia & 5 & 25 \\
Bronchopneumonia & 6 & 30 \\
Hemorrhagic pneumonia & 4 & 20 \\
Emphysema & 3 & 15 \\
Purulent pneumonia (focal) & 2 & 10 \\
\hline
\end{tabular}

Table 6. Prevalence of bacteria in lung $(\mathrm{N}=20)$

\begin{tabular}{|c|c|c|c|}
\hline Findings & Types of lung lesions & $\begin{array}{l}\text { No. of lungs } \\
\text { affected }\end{array}$ & $\begin{array}{l}\% \text { Bacterial } \\
\text { isolation }\end{array}$ \\
\hline Staphylococcus sp. & $\begin{array}{l}\text { Bronchopneumonia, purulent and focal } \\
\text { pneumonia }\end{array}$ & 8 & 40 \\
\hline E. coli & $\begin{array}{l}\text { Bronchopneumonia, hemorrhagic } \\
\text { pneumonia and pneumonia (severe) }\end{array}$ & 5 & 25 \\
\hline Pasteurella sp. & Pneumonia and hemorrhagic pneumonia & 3 & 15 \\
\hline $\begin{array}{l}\text { Mixed infection } \\
\text { (Staphylococcus sp. } \\
\text { and E. coli })\end{array}$ & $\begin{array}{l}\text { Bronchopneumonia hemorrhagic } \\
\text { pneumonia and purulent pneumonia }\end{array}$ & 4 & 20 \\
\hline
\end{tabular}

The prevalence of Staphylococcus sp. was recorded 40\% (8 out of 20 lungs). They grew well on nutrient agar media and showed smooth circular, opaque often yellow-pigmented colony about $1 \mathrm{~mm}$ in diameter after overnight of incubation at $37^{\circ} \mathrm{C}$. In nutrient broth, they grew well and showed dense turbidity with a powdery deposit. Smears from pure cultures revealed gram positive and round shaped bacteria occurring in cluster form. The prevalence of Pasteurella sp. was recorded 15\% (3 out of 20 lungs). They grew well on nutrient agar media and showed smooth, circular, grayish colony about $1 \mathrm{~mm}$ in diameter after overnight incubation at $37^{\circ} \mathrm{C}$. In nutrient broth, they grey well and showed diffuse turbidity. Small grayish hemolytic zones were evident in blood agar media. Smear from pure culture revealed gram negative, bipolar, small rod shaped bacteria. In Leishman's stain bipolar characteristics of the organisms were diagnosed which took blue color. Pasteurella sp. fermented the sucrose, dextrose, maltose with production of acid but did not ferment lactose. So, isolated organisms were Pasteurella sp. 
The prevalence of $E$. coli in lung swabs was $25 \%$ ( 5 out of 20 lungs). The organism produced smooth circular colonies with dark centers and metalic sheen on EMB agar. E. coli was a short rod, varying from coccoid bipolar shapes to long filamentous forms. It occurred singly or short chains and they were gram negative. Motility test was performed by hanging drop slide as mass movement was found (Merchant and packer, 1967). E. coil fermented dextrose, lactose, maltose, mannitol and sucrose. Two isolates of each group of $E$. coli were tested by ECO-f and ECO-r primer and showed 585-bp products after 1\% agarose gel electrophoresis and found clear band formation (Fig. 8).

\section{Antibiotics sensitivity test}

Staphylococcus sp. was slightly sensitive to penicillin while Pasteurella sp. and E. coli were resistant to penicillin. Staphylococcus sp., Pasteurella sp. and E. coli were highly sensitive to oxytetracycline, streptomycin, kanamycin and ciprofloxacin. Staphylococcus sp., Pasteurella sp. and E. coli were partially resistant to amoxicillin. Staphylococcus sp. was sensitive to nalidixic acid while Pasteurella sp. and E. coli were completely resistant to nalidixic acid (Table 5 and Fig. 9).

Table 5. Antibiotics (available in veterinary practice) sensitivity test on isolated bacteria

\begin{tabular}{|lccc|}
\hline Antibiotics & \multicolumn{3}{c|}{ Name of isolated bacteria } \\
\hline \multicolumn{1}{|c|}{ Staphylococcus sp. } & Pasteurella sp. & E. coli \\
\hline Penicillin & \pm & - & - \\
Oxytetracycline & + & + & + \\
Amoxycillin & $\pm^{*}$ & $\pm^{*}$ & + \\
Streptomycin & + & + & + \\
Ciprofloxacin & + & + & + \\
Kanamycin & + & + & - \\
Nalidixic acid & + & - & - \\
\hline
\end{tabular}

N.B: Partially sensitive $= \pm$, Partially resistant $= \pm *$, Sensitive $=+$ and Resistant $=-$

\section{DISCUSSION}

The present investigation was conducted on slaughtered goats in Mymensingh Sadar to categorize the different lung lesions, isolation of bacteria, and finally antibiotics sensitivity test (commonly used antibiotics in Veterinary practices) was performed on isolated bacteria. In the present study, the prevalence of gross lung lesions was recorded $40 \%$ in Black Bengal (it was not mentioned in M\&M and result sections) goat at Mymensingh in Bangladesh. Ferdausi et al. (2008) and Alam et al. (2001) recorded the gross lung lesions were $58.33 \%$ and $6.66 \%$, respectively. This variation compared to present investigation might be due to some calculating factor and frequency of diseases. Ugochukwu (1985) reported gross lung lesions of goat with an incidence of 75\%. But Almeida et al. (1986), Kaya and Erganis (1991) reported an incidence of 35.5\% and $55.8 \%$, respectively. On the basis of gross findings, this variation of incidence might be due to variation of geographical location or virulence of the causal agent. However, the findings of present investigation were almost similar to other authors (Almeida et al., 1986, 35.5\% and Kaya and Erganis, 1991, 55.8\%). Though geographical location and breeds of goats were different, the prevalence of lung lesion in present investigation was less than that of findings of Ugochukwu (1985) who reported 75\% incidence.

In this investigation, the highest prevalence of histopathological lung lesions was bronchopneumonia (30\%) and the isolated bacteria were Pasteurella sp. and E. coli from this lesion. The second highest prevalence of lungs lesions recorded $25 \%$ were pneumonia then hemorrhagic pneumonia (20\%) and emphysema (15\%). The less commonly occurring lungs lesions were purulent pneumonia $(10 \%)$ and the isolated bacteria was Staphylococcus sp. Ferdausi et al. (2008) reported that histopathologically the lung lesions were pneumonia $6.67 \%$, bronchopneumonia $3.33 \%$, purulent pneumonia $5 \%$, hemorrhagic pneumonia $3.33 \%$ etc. This variation might be due to some calculating factor as authors calculated out of total examined goat but this investigation was conducted within only affected lungs of goats. Histopathology of bronchopneurnomia and hemorrhagic pneumonia described in this present investigation corresponded to the lesions of other investigators (Jones et al., 1997; Alam et al., 2001; Akbor et al., 2007). 


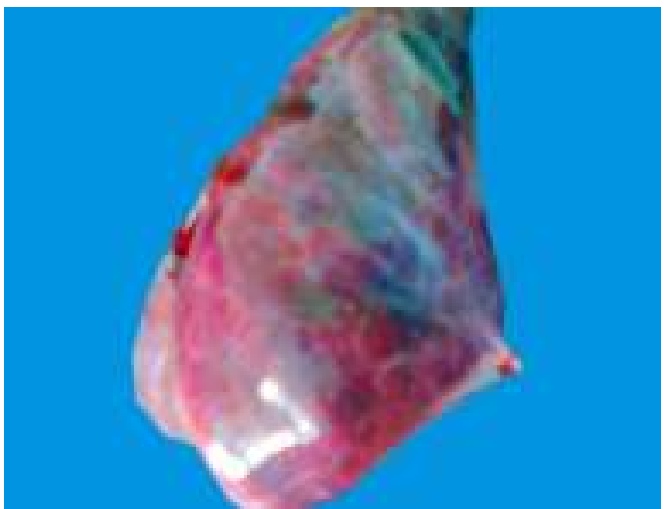

Figure 1. Red hepatization of lung

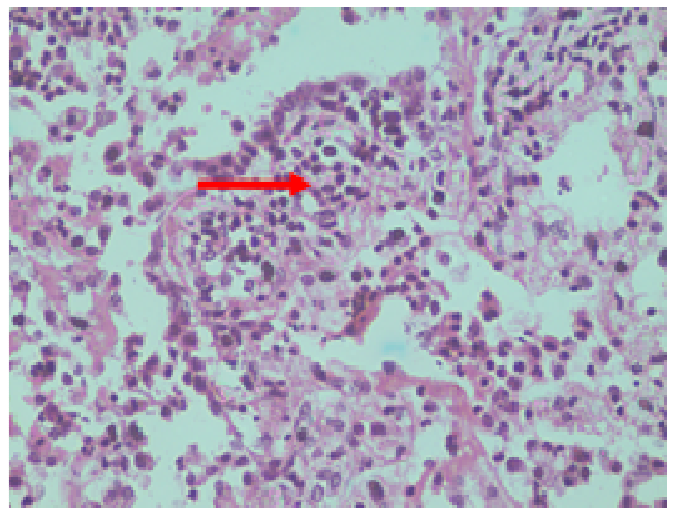

Figure 3. Section of goat lung showing pneumonia (severe) with E. coli (H \& E; 40X)

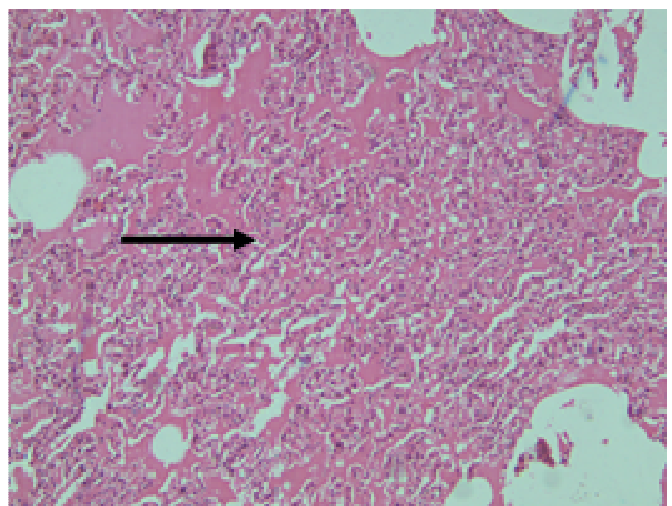

Figure 5. Section of goat lungs showing mixed infection with $E$. coli and Staphylococcus sp. by bronchopneumonia and hemorrhagic pneumonia (H \& E; 10X)

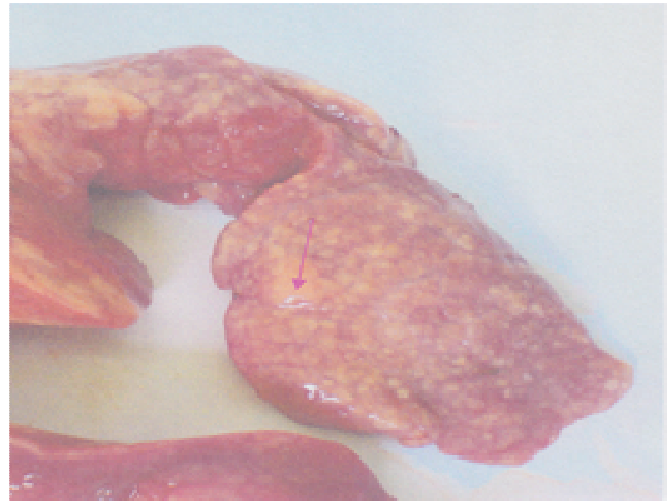

Figure 2. Gray hepatization of lung

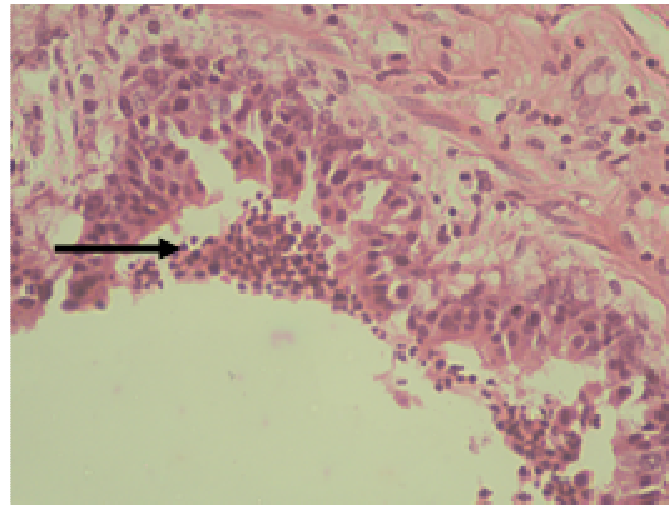

Figure 4. Section of goat lung showing bronchopneumonia with $E$. coli infection with $(\mathrm{H} \& \mathrm{E}$; 40X)

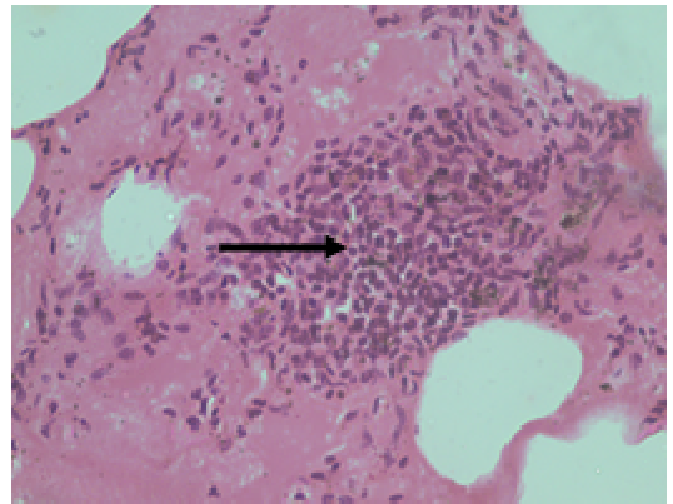

Figure 6. Section of goat lung showing focal purulent pneumonia with Staphylococcus sp. infection (H \&E ; 40X) 


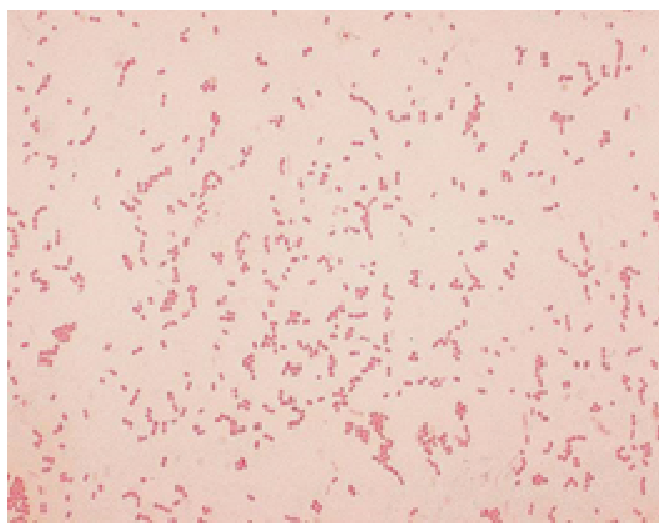

Figure 7. Smear from pure culture of Pasteurella sp. and stained with Gram's stain: Gram negative bipolar rod shaped bacteria

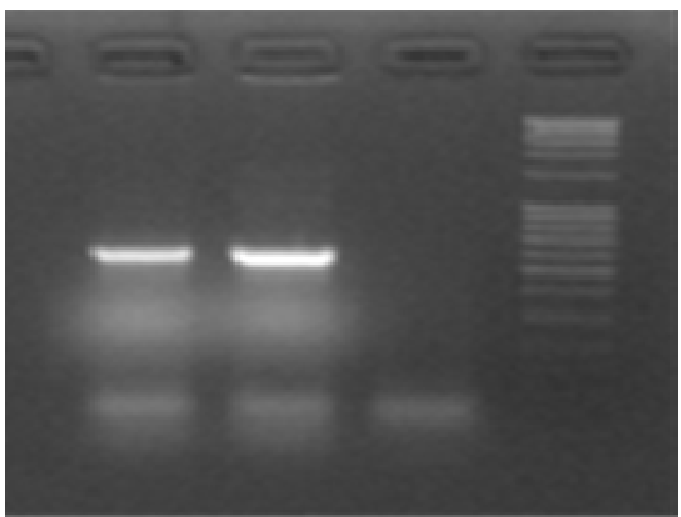

Figure 8. $\mathrm{M}=100 \mathrm{bp}$ Marker, $\mathrm{NC}=$ Negative control, $\mathrm{S} 1=$ sample 1 of $\mathrm{E}$. coli isolate and $\mathrm{S} 2=$ sample 2 of $\mathrm{E}$. coli isolate

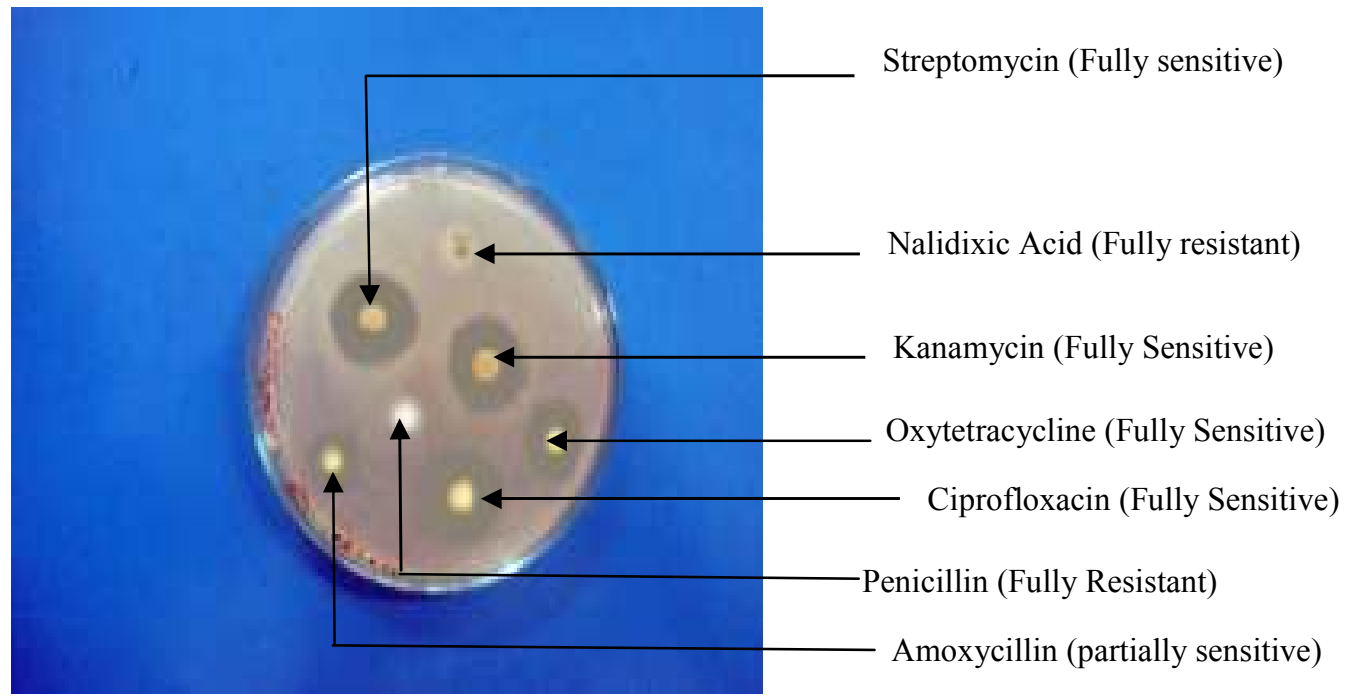

Figure 9. Antibiotics sensitivity test on isolates of E. coli

In this investigation three types of bacteria like Pasteurella sp. (15\%), Escherichia coli (25\%) and Staphylococcus $s p$. (40\%) were isolated and identified by cultural character, staining properties and by PCR for E. coli only by using primer (ECO-r and ECO-f). Ferdausi et al. (2008) reported Pasteurella sp. (11.67\%), Staphylococcus sp. (36.67\%) and Bacillus sp. (3.33\%). This investigation could not find out Baillus sp. but isolation of Staphylococcus sp. (40\%) and Pasteurella sp. (15\%) were almost similar to that of findings. Pasteurella sp. was isolated from pneumonia, hemorrhagic pneumonia and emphysematous lungs. E. coli was isolated from bronchopneumonia and severe pneumonia.

In bronchopneumonia the peribronchial tissue of the bronchus showed severe inflammatory lesions. So, on the basis of this finding, it might be speculated that the path of infection was in bronchogenous route. However, in recent theory whatever the route of infection, the severity of lesion depends on the virulence of causal agent (Jones et al., 1997). The histopathological lesions of pneumonia and emphysema were similar with the description of other authors (Jones et al., 1997; Alam et al., 2001; Akbar et al., 2007). 


\section{M. Rashid and others}

Staphylococcus sp. was isolated from focal pneumonia and purulent pneumonia. As this bacteria is known as pyogenic bacteria that's why it might be speculated that this purulent pneumonia was produced by the infection of Staphylococcus sp. The lesion of purulent pneumonia was scattered in the lung parenchyma. On the basis of the distribution of lung lesion, the path of infection might be due to hematogenous route.

Staphylococcus sp. was slightly sensitive to penicillin while Pasteurella sp. and E. coli were resistant to penicillin. Staphylococcus sp., Pasteurella sp. and E. coli were highly sensitive to oxytetracycline, streptomycin, kanamycin and ciprofloxacin. Staphylococcus sp., Pasteurella sp. and E. coli were partially resistant to amoxicillin. Staphylococcus sp. was sensitive to nalidixic acid while Pasteurella sp. and E. coli were completely resistant to nalidixic acid..

Finally, this study on lung lesions in goat has focused the different disease conditions and antibiotics sensitivity test on isolated bacteria. In maximum cases, the frequency of pathogenicity of causative agents was not studied from the lesions. In near future, the attempts should be taken to detect the pathogenicity of the causative agents.

\section{REFERENCES}

1. Akbor A, Haider MG, Ahmedullah F, Khan MAHNA, Hossain MJ and Hossain MM (2007). Pathology of trachea and lungs of buffaloes. Bangladesh Journal of Veterinary Medicine 5 (1-2): 87-91.

2. Alam KJ, Hossain MM, Bari ASM, Chowdhury EH, Hossain AKMA and Islam MA (2001). Etiopathological investigation of systemic diseases in slaughtered Black Bengal Goats. 1. Respiratory System. Bangladesh Veterinary Journal 35(1-2):53-58.

3. Almeida PF, Alves FSF, Santos LdeF and Rosa JS (1986). Survey on bacterial agents associated with respiratory disease of goats in North Eastern Brazil. Revista de Microbiology. 17 (3):213-215.

4. Dipti M (2013). Morphological and immunological characterization of anthrax vaccine bacteria in cattle. M S Thesis Submitted to Department of Pathology, Bangladesh Agricultural University, Mymensingh.

5. Ferdausi T, Haider MG, Alam KJ, Baki MA and Hossain MM (2008). Caprine lung diseases and causal bacteria. The Bangladesh Veterinarian 25 (1): 9-16.

6. Jones TC, Hunt RD and King NW (1997). Veterinary Pathology. 6th edition, Williams and Wilkins. pp. 345.

7. Kaya O and Erganis O (1991). Aetiological survey of pneumonia in sheep and lambs. Vetrinarium 2 (3-4) 27-29.

8. Luna LG, (1968). Manual of Histologic Staining Methodes of the Armed Forces Institute of Pathology. $3^{\text {rd }}$ ed. Mcgraw Hill Book Co. New York. 44 pp. 53-89.

9. Merchant IA and Packer RA (1967). Veterinary Bacteriology and Virology, 7th Edn. The Iowa University Press, Ames, Iowa, USA. pp. 286-306.

10. Rahman A, Ahmed MU and Mia AS (1976). Studies on the diseases of goats in Bangladesh. Mortality of goats under farm and rural conditions. Tropical Animal Health Production 8 (2) 90.

11. Tonu NS, Sufian MA, Sarker S, Kamal MM, Rahman MH and Hossain MM ( 2011). Pathological study on colibacillosis in chicken and detection of Escherichia coli by PCR. Department of Pathology, Faculty of Veterinary Science, BAU, Mymensingh-2202, Bangladesh. Bangladesh Journal of Veterinary Medicine 9 (1) $17-25$.

12. Ugochukwu EI (1985). Isolation and identification of aerobic pathogenic bacteria from pneumonic lungs of goats suffering from pneumonia enteritis complex. Bulletin of Animal Health and Production Africa. 33 303-306. 